\title{
DNA Methylation of the RiZ1 Tumor Suppressor Gene Plays an Important Role in THE Tumorigenesis of CERVICAL CANCER
}

\author{
H. Y. Cheng, Y. Gao, G. Lou \\ Department of Gynecologic Oncology, The Tumor Hospital of Harbin Medical University, Heilongjiang, China
}

\begin{abstract}
Abtract
Objective: The retinoblastoma protein-interacting zinc finger gene RIZ1 is a tumor suppressor gene and a member of a nuclear histone/protein methyltransferase superfamily. The purpose of the present study was to examine the expression of RIZ1 and evaluate its carcinogenesis in cervical cancer. The relationship between DNA methylation and transcriptional silencing of RIZ1 was investigated in cervical cancer.

Methods: RIZ1 expression was examined in cervical cancer cell lines and cervical tissues (12 normal and 40 cancerous) by using RT polymerase chain reaction (PCR). Methylation status of the RIZ1 promoter was studied using methylation-specific PCR (MSP).

Results: RIZ1 expression is reduced or lost in cervical cancers, compared with normal cervical tissues ( $P$ $<0.05)$. The current study results also showed that loss of RIZ1 is mediated by aberrant cytosine methylation of the RIZ1 promoter. $37.5 \%$ of carcinomas were methylated, while none of normal tissues were methylated. RIZ1 mRNA expression was significantly higher $(\mathrm{P}=0.000)$ in unmethylated $(0.3494 \pm 0.0466$, mean $\pm \mathrm{SD})$, compared with methylated tissues $(0.1422 \pm 0.1073$, mean $\pm S D)$. Treatment with a DNA methyltransferase inhibitor led to reactivation of RIZ1 expression in cell lines that had negligible RIZ1 expression at baseline.

Conclusions: Reduced expression of RIZ1 may play an important role in the pathogenesis and/or development of cervical cancer, and is considered to be caused in part by aberrant DNA methylation.
\end{abstract}

Key words: RIZ1, cervical cancer, methylation

\section{INTRODUCTION}

Epigenetic phenomena such as DNA methylation and alterations in the chromatin structure are increasingly recognized as important mechanisms that are responsible for tumor-suppressor inactivation. Recent studies have shown that promoter hypermethylation is an important mechanism in transcriptional silencing of genes during cervical carcinogenesis. Investigations by various authors have demonstrated that expression levels of p16, RASSF1A, DNMT3L, FHIT, COX-2 and DAPK are altered by promoter hypermethylation in cervical cancers [1-5].

The retinoblastoma protein-interacting zinc finger gene (RIZ or PRDM2) was initially isolated in a func- tional screening for Rb-binding proteins [6]. RIZ is a member of the nuclear protein methyltransferase superfamily. The gene maps to chromosome $1 \mathrm{p} 36$, a region commonly deleted in more than a dozen different types of human cancers [7]. RIZ1 produces two mRNA and protein products. RIZ1 contains a novel protein methyltransferase domain, whereas RIZ2 lacks this domain [8]. RIZ1, but not RIZ2, has been shown to have tumor suppressor activity. RIZ1 knockout mice have increased tumor susceptibility [9]. Adenovirus-mediated RIZ1 expression causes G2-M cell cycle arrest and/or apoptosis in breast cancer, liver cancer, and microsatellite instability-positive colon cancer cells [10-12]. RIZ1 expression, but not RIZ2 expression, is commonly silenced in many types of human tumors, including breast cancer, thyroid cancer, liver cancer, colon cancer, neuroblastoma,melanoma, lung cancer, and osteosarcoma [10-13].

DNA methylation has an essential regulatory function in mammalian development, suppressing gene activity by changing chromatin structure $[14,15]$. It has become apparent that aberrant DNA methylation of promoter region $\mathrm{CpG}$ islands may serve as an alternate mechanism to genetic defects in the inactivation of tumor suppressor genes in human malignancies $[16,17]$. Promoter hypermethylation has been shown to be associated with reduced RIZ1 expression in solid tumors, such as gastric and gallbladder carcinomas, in addition to leukemias [18-21]. Treatment with a DNA methyltransferase inhibitor, 5-aza-2'deoxycytidine (5aza-dC) has been shown to activate RIZ1 mRNA expression in carcinoma cell lines that have reduced RIZ1 expression at baseline $[18,22,23]$. RIZ1 missense inactivating mutations have also been described [24-26]. Interestingly, all of these have been shown to be restricted to the protein methyltransferase domain, which expresses protein methyltransferase activity [22].

The expression and role of RIZ1 have not been examined in cervical cancers. Our results show that RIZ1 mRNA expression is reduced or lost in cervical cancer and associated with promoter methylation.

\section{Materials And Methods \\ Cell Lines and Tissues}

We obtained four cervical cancer cell lines (HeLa, SiHa, CaSki and C33) from the American Type Culture Collection (Manassas, VA, USA). All cell lines 
were grown in DMEM (Invitrogen, Carlsbad, CA) plus $10 \%$ FCS (Invitrogen, Carlsbad, CA) at $37^{\circ} \mathrm{C}$ and $5 \% \mathrm{CO}_{2} .12$ normal cervix and 40 cervical cancer tissues(two adenocarcinoma and 38 squamous cell carcinoma) were obtained from the Tumor Hospital of Harbin Medical University. The tissues were harvested and frozen in liquid nitrogen at the time of operation. The samples were stored at $-70^{\circ} \mathrm{C}$ until further use.Informed consent was abtained from all study participants.

\section{DRUg TREATMENT}

Cancer cells ( $5 \times 10^{6}$ cells) were grown for 4 days in the presence of various concentrations of 5 -aza- $2^{\circ}$-deoxycytidine (5-aza-dC; Sigma, St. Louis, Mo, USA), a known DNA methyltransferase inhibitor. Total RNA was isolated and used for RT-PCR analysis as described below. Genomic DNAs were isolated from treated and nontreated cells and used for MSP assays as described below.

\section{Reverse Transcription and Semi-Quantitative RT- PCR}

Total RNA was isolated from cervical tissues and cell lines using TRIzol (Invitrogen, Carlsbad, CA). Reverse transcription was performed using M-MLV reverse transcriptase and random oligonucleotide. The firststrand cDNA sample was then amplified using 5'CATACAACTGAAGACAAGTGAG-3' and 5'-TAA 'TCGCTCGTCTGGT'TC-3' (208 bp). The primers for amplification of human $\beta$-actin are $5^{\prime}-\mathrm{GTG}$ GGG CGC CCC AGG CAC CA-3'and 5'-CTCCTTAAT GTCACGCACGATT'TC-3'. PCR reactions were run for 30 cycles. The PCR products were analysed by gel electrophoresis followed by ethidium bromide staining.

\section{DNA Extraction and Methylation Analysis}

Genomic DNAs from tumor tissues and cell lines were extracted using Universal Genomic DNA Extraction Kit Ver 3.0 (Takara, Tokyo, Japan). The quality and integrity of the DNAwas determined by the A260/280 ratios. Genomic DNA (1 $\mathrm{gg})$ was modified with sodium bisulfite using EZ-DNA methylation kit (Zymo research, Orange, CA). Bisulfite-treated DNA was used for methylation-specific PCR by using previously published primer sets [22] to distinguish between methylated and unmethylated DNA. The PCR products were electrophoresed on a $2 \%$ agarose gel.

\section{Statistical AnALysis}

Gene expression levels are reported as mean \pm standard deviation (SD). RIZ1 mRNA expression levels were normal distribution and equal variances, which were compared by using $\mathrm{T}$ Test. The correlation between methylation frequencies and clinicopathological characteristics was compared with the Fisher exact test. All statistical tests were 2 -sided and performed at the $5 \%$ level of significance using the SPSS10.0 software package.

\section{RESULTS}

RIZ1 mRNA Expression in Cervical Cancer Cell Lines AND Primary Tumors

To study the expression of RIZ1 gene in cervical cancer, we performed RT-PCR analysis. RIZ1 expression was reduced or lost in three of four cervical cancer cell lines (Fig. 1a). RIZ1 mRNA expression levels in normal and primary tumor tissues are shown in Figure $1 \mathrm{~b}$ and Table 1. RIZ1 mRNA expression in cervical cancer tissues was significantly lower than that in normal tissues $(\mathrm{P}=0.000)$

Table1. RIZ1 mRNA expression levels in normal cervical tissues and tumors.

\begin{tabular}{lllllll}
\hline & $\mathrm{n}$ & mean & $\mathrm{SD}$ & $\mathrm{SE}$ & $\mathrm{t}$ & $\mathrm{P}$ \\
\hline Normal & 12 & 0.5227 & 0.094 & 0.0271 & & \\
Malignant & 40 & 0.2717 & 0.1256 & 0.0199 & & \\
\hline
\end{tabular}

SD indicates standard deviation; SE, standard error; $\mathrm{p}<0.05$

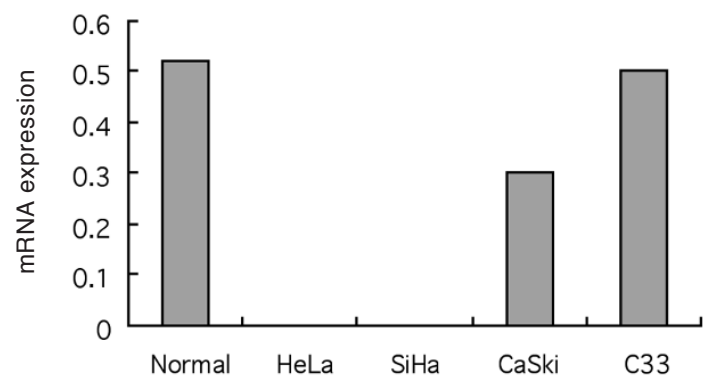

a
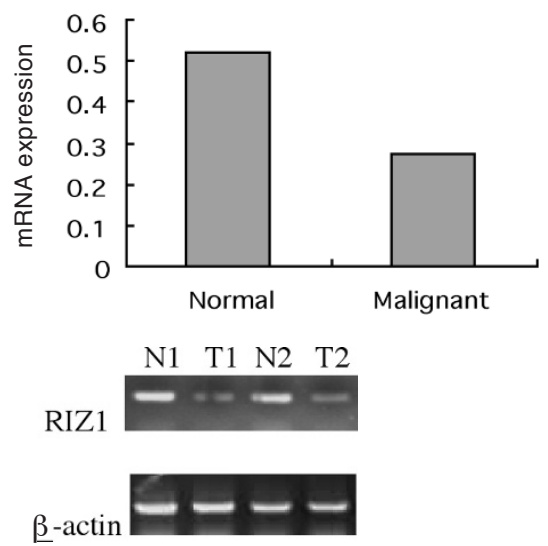

b

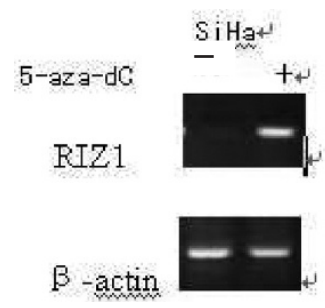

Fig. 1. (a) RIZ1 mRNA in cervical cancer cell lines relative to normal tissues $(\mathrm{n}=12)$. RIZ1 mRNA expression was absent in 2 of 4 cervical cancer cell lines . (b) RIZ1 mRNA expression in normal tissues $(\mathrm{N})$ and match tumor tissues(T). RIZ1 mRNA expression in cervical cancer tissues was significantly lower than that in normal tissues $(\mathrm{P}<0.05)$. (c) Reactivation of RIZ1 expression by inhibitor of DNA methylation in SiHa cells. 
To determine whether DNA methylation plays a role in silencing RIZ1 gene expression, we investigated whether RIZ1 expression can be activated by 5 -aza$\mathrm{dC}$, an inhibitor of DNA methylation. SiHa cells were treated with $1 \mathrm{uM}$ of 5 -aza-dC for 4 days. By RT-PCR analysis, 5-aza-dC treatment reactivated RIZ1 expression (Fig. 1c). This result suggests a probable role of DNA methylation in silencing RIZ1 gene expression.

\section{RiZ1 Promoter Methylation Status in Cervical Cancer Cell Lines and Primary Tumors}

As shown in Figure 2a, methylation of RIZ1 promoter CpG island was found in HeLa and $\mathrm{SiHa}$ cancer cells. In contrast, the promoter was unmethylated in C33 cell line, which had retained RIZ1 expression. Both methylated and unmethylated products were observed in the CaSki cell line, which displayed decreased (but detectable) amounts of RIZ1 expression.

RIZ1 promoter methylation frequency was also examined in normal and primary cervical cancer tissues by methylation specific PCR.15 of 40 (37.5\%) carcinomas showed evidence of RIZ1 promoter methylation, ie, a band was detected by using primers specific for the methylated product. Only unmethylated band was detected in all normal cervical tissues (Fig. 2a). To determine whether transcriptional silencing of RIZ1 is significantly associated with promoter hypermethylation in cervical cancer tissues, we assessed the correlation between methylation status and RIZ1 mRNA expression. RIZ1 mRNA expression was significantly higher $(\mathrm{P}=0.000)$ in unmethylated $(0.3494 \pm 0.0466$, mean $\pm \mathrm{SD})$, compared with methylated tissues $(0.1422$ \pm 0.1073 , mean \pm SD), as shown in Figure $2 b$. No significant correlation was detected between methylation status and clinicopathological characteristics,as shown in Table 2.

We also used MSP assay to test whether demethylation might be induced by 5 -aza-dC treatment, which may correlate with reactivation of RIZ1 expression in
Table 2. Correlation between RIZ1 methylation and clinicopathological parameters in cervical cancer.

\begin{tabular}{ccc}
\hline Factor & \multicolumn{2}{c}{ Methylation* } \\
& $\%(\mathrm{Me} /$ total $)$ & P-value \\
\hline $\begin{array}{c}\text { Tumor size }(\mathrm{cm}) \\
<4\end{array}$ & $34.6(9 / 26)$ & 0.736 \\
$\geq 4$ & $42.9(6 / 14)$ & \\
Tumor grade & $34.8(8 / 23)$ & 0.749 \\
G1+G2 & $41.2(7 / 17)$ & \\
G3 & $46.7(7 / 15)$ & 0.502 \\
Tumor stage & $32.0(8 / 25)$ & \\
I & $33.3(10 / 30)$ & 0.457 \\
II+III & $50.0(5 / 10)$ & \\
pelvic lymph nodes & \\
Negative & \\
Positive &
\end{tabular}

*Samples that showed partials methylation are included

SiHa cell. As shown in Figure 2c, 5-aza-dC treatment led to an increase in the proportion of unmethylated DNA versus methylated DNA.

\section{Discussion}

Silencing of tumor suppressor genes is important in initiation and progression of cancers. RIZ1 has been reported to possess tumor suppressor activity, and its expression is lost in many carcinoma cell lines and primary tumors. The expression and role of RIZ1 have not been examined in cervical cancers. We hypothesized that loss of RIZ1 expression is important in cervical tumorigenesis and that this is mediated by hypermethylation (which can be inhibited by 5 -aza-dC). Because promoter hypermethylation is strongly associated with loss of mRNA expression,we then examine
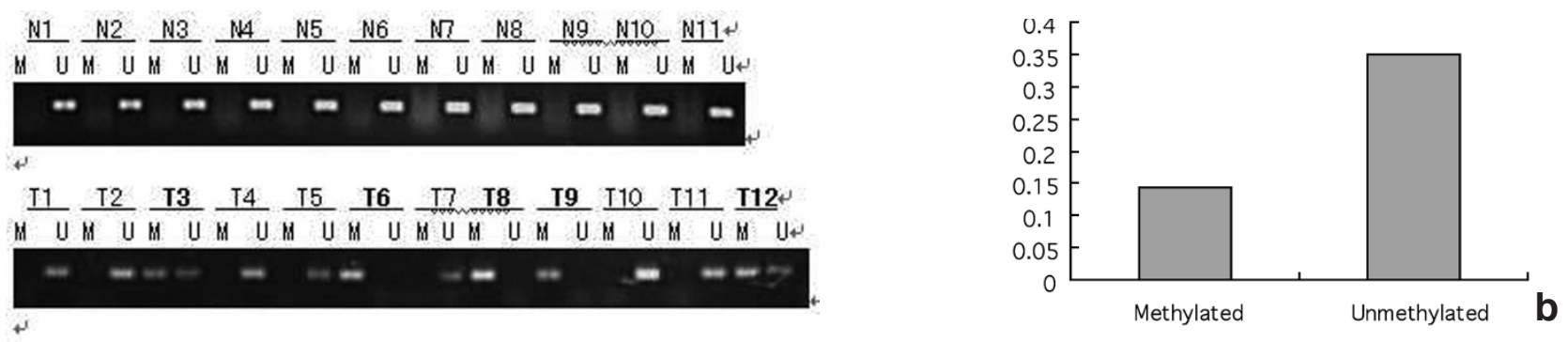

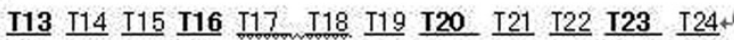

MU MU MU MU MU MU MU M U MU MU MU MU
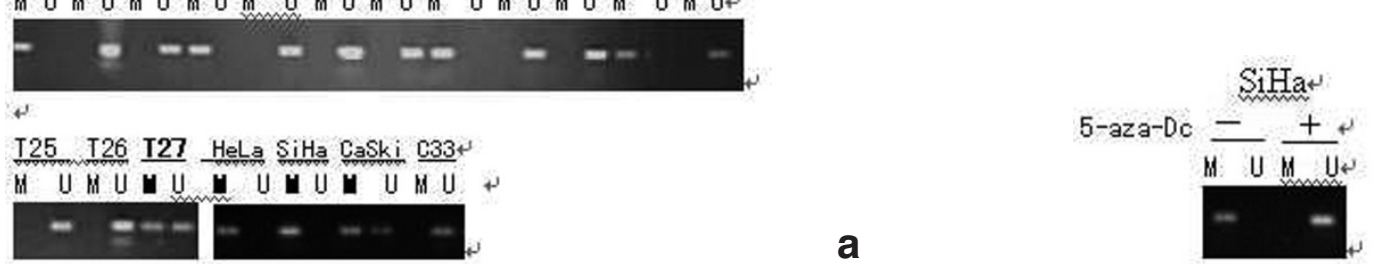

Fig. 2. a) Methylation-specific PCR analysis of various cervical cancer cell lines and all of primary tumors and normal tissues. Bisulfite-treated DNA was used as a template for methylation-specific PCR by using previously described primers. $M=$ primers specific to methylated template DNA, $\mathrm{U}=$ primers specific to unmethylated template DNA, $\mathrm{T}=$ tumor, $\mathrm{N}=$ normal $\mathrm{b}$ ) RIZ1 mRNA expression in methylated and unmethylated cervical cancer tissues. c) Methylation status of SiHa cell line before and after treatment with the DNA methyltransferase-inhibiting agent, 5-aza-dC. 
the promoter methylation status of RIZ1 in cervical cancer cells and tissues. In our study, the RIZ1mRNA expression in cervical cancer tissues was significantly lower than that in normal cervical tissues $(\mathrm{P}<0.05)$. RIZ1 expression was reduced or lost in three of four cervical cancer cell lines. These results suggest that RIZ1 may function as a potential tumor suppressor gene in cervical cancer, as in other malignant tumors.

The RIZ1 promoter has been demonstrated to have the characteristics of a $\mathrm{CpG}$ island, which suggests that RIZ1 is a target of inactivation by epigenetic mechanisms [22]. DNA methylation was a common mechanism of gene silencing. In prostate cancer, $42.6 \%$ of cancer cases were reported to have methylation of RIZ1 [27]. In gastric adenocarcinoma, hypermethylation of RIZ1 was found in $69 \%$ of cancer tissues and in $21 \%$ of corresponding non-neoplastic mucosa [18]. In thyroid carcinoma, all of the 19 cancer cases were methylated, and was significantly frequent compared with normal thyroid tissues (33\%) [13]. Du et al. reported that methylation of RIZ1 was detected in $44 \%$ of breast cancer specimens and $62 \%$ of liver cancer specimens [22]. In the present study the RIZ1 mRNA expression was low or undetected in cervical cancer tissues and cell lines. The $\mathrm{SiHa}$ cell line was treated with 5-aza-dC (methyltransferase inhibitor), in order to determined whether DNA methylation was the cause of transcriptional silencing of RIZ1.In the $\mathrm{SiHa}$ cell line the mRNA expression of RIZ1 was recovered after treatment with 5 -aza-dC, indicating that aberrant DNA methylation is likely to cause transcriptional silencing. Our data show that the incidence of RIZ1 gene promoter methylation was relatively less frequent compared with previous studies noted. Methylation was found in $37.5 \%(15 / 40)$ of cervical cancer tissues and none of normal cervical tissues. The difference reached statistical significance ( $P$ $<0.05)$. Furthermore,in the cervical cancer tissues the RIZ1 mRNA expression was obviously higher in the unmethylated than that in the methylated $(\mathrm{P}<0.05)$, which suggests that methylation of the RIZ1 promoter may contribute to cervical carcinogenesis. We found no correlation between methylation and any of the clinicopathological characteristics of the patients.

In the present study the unmethylated form of the RIZ1 promoter was detected in tumor and normal samples. It is not surprising because the samples were not separated using laser-capture microdissection, and thus they can be expected to contain both normal and tumor tissues. Several cases demonstrated relatively low levels of RIZ1 expression in the absence of RIZ1 promoter methylation. We speculate that there may be other mechanisms that are involved in RIZ1 gene silencing. Such mechanisms may include histone methylation, mutations in promoter sequences and DNA methylation in other promoter regions not covered by our present PCR primer set.

The present results suggest that RIZ1 is a potential tumor suppressor gene and transcriptional silencing of this gene is caused in part by DNA promoter methylation in cervical cancer. It is also suggested that epigenetic silencing of RIZ1 (e.g., methylation of its 5-CpG island) plays an important role in the progression of cervical cancer, and may be a useful molecular target for diagnosis and therapy. Infection with oncogenic HPV is the most significant risk factor in cervical cancer. Transcriptional inactivation of the RIZ1 gene may be induced by oncogenic HPV. The association between the RIZ1 methylation and HPV genotypes will be investigated in the future.

Acknowledgments: We thank Yi-hui Fan for their excellent technical assistance.

\section{REFERENCES}

1 Yu MY, Tong JH, Chan PK, Lee TL, Chan MW, Chan AW, Lo KW, To KF. Hypermethylation of the tumor suppressor gene RASSFIA and frequent concomitant loss of heterozygosity at $3 \mathrm{p} 21$ in cervical cancers. Int J Cancer. 2003Jun;105(2):204-9

2. Gokul G, Gautami B, Malathi S, Sowjanya AP, Poli UR, Jain M, Ramakrishna G, Khosla S. DNA methylation profile at the DNMT3L promoter: a potential biomarker for cervical cancer.Epigenetics. 2007 Apr-Jun ;2(2):80-5.

3. Wu Y, Meng L, Wang H, Xu Q, Wang S, Wu S, Xi L, Zhao Y, Zhou J, Xu G, Lu Y, Ma D. Regulation of DNA methylation on the expression of the FHIT gene contributes to cervical carcinoma cell tumorigenesis. Oncol Rep. 2006 Sep;16(3):625-9.

4. Jo H, Kang S, Kim JW, Kang GH, Park NH, Song YS, Park SY, Kang SB, Lee HP. Hypermethylation of the COX-2 gene is a potential prognostic marker for cervical cancer.J Obstet Gynaecol Res. 2007 Jun ;33(3):236-41

5. Jeong DH, Youm MY, Kim YN, Lee KB, Sung MS, Yoon HK, Kim KT. Promoter methylation of p16, DAPK, CDH1, and TIMP-3 genes in cervical cancer: correlation with clinicopathologic characteristics. Int J Gynecol Cancer. 2006 May-Jun; 16(3):1234-40

6. Buyse IM, Shao G, Huang S. The retinoblastoma protein binds to RIZ, a zinc-finger protein that shares an epitope with the adenovirus E1A protein. Proc Natl Acad Sci U S A. 1995 May;92:4467-4471.

7. Weith A, Brodeur GM, Bruns GA, Matise TC, Mischke D, Nizetic D, Seldin MF, van Roy N, Vance J. Report of the Second International Workshop on Human Chromosome 1 Mapping 1995. Cytogenet. Cell Genet., 1996;72(23): $114-144$

8. Huang S, Shao G, Liu L. The PR domain of the Rb-binding zinc finger protein RIZ1 is a protein binding interface and is related to the SET domain functioning in chromatinmediated gene expression. J Biol Chem. 1998 Jun 26; 273: 15933-15939.

9. Steele-Perkins G, Fang W, Yang XH, Yang XH, Van Gele M, Carking T, Gu J, Buyse IM, Fletcher JA, Liu J, Bronson R, Chadwick RB, de la Chapelle A, Zhang X, Speleman F, Huang S. Tumor formation and inactivation of RIZ1, an Rb-binding member of a nuclear proteinmethyltransferase superfamily. Genes Dev. 2001 Sep; 15(17): 2250-2262.

10. He L., Yu JX, Liu L, Buyse IM, Wang MS, Yang QC, Nakagawara A, Brodeur GM, Shi YE, Huang S. RIZ1, but not the alternative RIZ2 product of the same gene, is underexpressed in breast cancer, and forced RIZ1 expression causes G2-M cell cycle arrest and/or apoptosis. Cancer Res 1998 Oct 1;58(19): 4238-4244

11. Jiang GL, Liu L, Buyse IM, Simon D, Huang S. Decreased RIZ1 expression but not RIZ2 in hepatoma and suppression of hepatoma tumorigenicity by RIZ1. Int J Cancer. 1999 Nov;83(4): 541-547

12. Jiang GL, Huang S. Adenovirus expressing RIZ1 in tumor suppressor gene therapy of microsatellite-unstable colorectal cancers. Cancer Res 2001 Mar1; 61(5):1796-8. 
13. Lal G, Padmanabha L, Smith BJ, Nicholson RM, Howe JR, O'Dorisio MS, Domann FE Jr. RIZ1 is epigenetically inactivated by promoter hypermethylation in thyroid carcinoma. Cancer 2006 Dec15; 107(12): 2752-9.

14. Kass SU, Pruss D, Wolffe AP. How does DNA methylation repress transcription? Trends Genet 1997 Nov; 13(11): 444-9.

15. Razin A, Ceder H. DNA methylation and gene expression. Microbiol Rev 1991Sep; 55(3): 451-8.

16. Jones PA, Laird PW. Cancer epigenetics comes of age. Nat Genet 1999 Feb; 21(2): 163-7.

17. Esteller M, Corn PG, Baylin SB, Herman JG. A gene hypermethylation profile of human cancer. Cancer Res 2001Apr; 61(8):3225-9.

18. Oshimo Y, Oue N, Mitani Y, Mitani Y, Nakayama H, Kitadai Y, Yoshida K, Chayama K, Yasui W. Frequent epigenetic inactivation of RIZ1 by promoter hypermethylation in human gastric carcinoma. Int J Cancer. 2004 Jun;110(2):212-218.

19. Takahashi T, Shivapurkar N, Riquelme E, Shigematsu H, Reddy J, Suzuki M, Miyajima K, Zhou X, Bekele BN, Gazdar AF, Wistuba II. Aberrant promoter hypermethylation of multiple genes in gallbladder carcinoma and chronic cholecystitis. Clin Cancer Res. 2004 Sep; 10(18 Pt 1): 6126-6133.

20. Matsushita C, Yang Y, Takeuchi S, Matsushita M, Van Dongen JJ, Szczepanski T, Bartram CR, Seo H, Koeffler HP, Taguchi H. Aberrant methylation in promoter-associated CpG islands of multiple genes in relapsed childhood acute lymphoblastic leukemia. Oncol Rep. 2004 Jul; 12(1):97-99.

21. Huang $\mathrm{S}$. The retinoblastoma protein-interacting zinc finger gene RIZ in 1p36-linked cancers. Front Biosci. 1999 Jun 15;4:D528-D532.

22. Du Y, Carling T, Fang W, Piao Z, Sheu JG, Huang S. Hypermethylation in human cancers of the RIZ1 tumor suppressor gene, a member of a histone/protein methyltransferase superfamily.Cancer Res. 2001 Nov 15;61(22): 80948099 .
23. Schulmann K, Sterian A, Berki A, Yin J, Sato F, Xu Y, Olaru A, Wang S, Mori Y, Deacu E, Hamilton J, Kan T, Krasna MJ, Beer DG, Pepe MS, Abraham JM, Feng Z, Schmiegel W, Greenwald BD, Meltzer SJ. Inactivation of p16, RUNX3, and HPP1 occurs early in Barrett's-associated neoplastic progression and predicts progression risk. Oncogene. 2005 Jun 9; 24(25):4138-4148.

24. Jiang GL, Huang S. The yin-yang of PR-domain family genes in tumorigenesis. Histol Histopathol 2000 Jan; 15(1): 109-17.

25. Piao Z, Fang W, Malkhosyan S, Kim H, Horii A, Perucho M, Huang S. Frequent frameshift mutations of RIZ in sporadic gastrointestinal and endometrial carcinomas with microsatellite instability. Cancer Res 2000 Sep 1; 60(17): 4701-4.

26. Steele-Perkins G, Fang W, Yang XH, Van Gele M, Carling T, Gu J, Buyse IM, Fletcher JA, Liu J, Bronson R, Chadwick RB, de la Chapelle A, Zhang X, Speleman F, Huang S. Tumor formation and inactivation of RIZ1, an $\mathrm{Rb}$-binding member of a nuclear protein-methyltransferase superfamily. Genes Dev 2001 Sep 1; 15(17): 225062.

27. Hasegawa Y, Matsubara A, Teishima J, Seki M, Mita K, Usui T, Oue N, Yasui W. DNA methylation of the RIZ1 gene is associated with nuclear accumulation of p53 in prostate cancer. Cancer Sci 2007 Jan; 98(1): 32-6.

Received: December 12, 2008 / Accepted: June 9, 2009

Address for correspondence:

Ge Lou

Department of Gynecologic Oncology

The Tumor Hospital of Harbin Medical University

150 Haping road

Heilongjiang,150081

China

Tel.: $\quad$ 86-451-86298303

Fax: 86-451-86298390

E-mail: dr_lg@163.com 